\title{
Phytotoxic potential of selected medicinal plants on germination of Lactuca sativa seeds
}

Hussan Ara Begum ${ }^{1 *}$, Mohammad Hamayun ${ }^{1}$, Noor Shad ${ }^{2}$, Tabassum Yaseen $^{3}$ and Nighat Seema ${ }^{4}$

1. Department of Botany Abdul Wali Khan University Mardan-Pakistan

2. Department of Biochemistry Abdul Wali Khan University Mardan-Pakistan

3. Department of Botany, Bacha khan University Charsadda-Pakistan

4. Department of Botany, Govt, Girls Degree College Sheikh Maltoon Town Mardan-Pakistan

*Corresponding author's email: hussanara.begum@gmail.com

Citation

Hussan Ara Begum, Mohammad Hamayun, Noor Shad, Tabassum Yaseen and Nighat Seema. Phytotoxic potential of selected medicinal plants on germination of Lactuca sativa seeds. Pure and Applied Biology. Vol. 8, Issue 2, pp1605-1614. http://dx.doi.org/10.19045/bspab.2019.80103

\begin{tabular}{llll}
\hline \hline Received: 31/01/2019 & Revised: 03/06/2019 & Accepted: 10/06/2019 & Online First: 15/06/2019 \\
\hline
\end{tabular}

\section{Abstract}

Medicinal plants are best sources to treat various illnesses with them. So they might prove be a good source of developing novel herbicides. The aim of the present study was to investigate the potential inhibition effects of Cucumis sativus, Portulaca oleracea, Malus baccata, Saxifraga flagillaris, Geranium wallichianum and Monotheca buxifolia powdered material on germination of Lactuca sativa seeds. Sandwich method was used for determining phytotoxicity of these plants in terms of radicle and plumule length of Lactuca sativa seeds with different amounts of 10, 20, and 40mg of powdered plant material. Cucumis sativus and Monotheca buxifolia were found the most phytotoxic among the selected medicinal plants at all concentration. The results can be sum off as Monotheca buxifolia $>$ Cucumis sativus $>$ Malus baccata $>$ Saxifraga flagillaris $>$ Geranium wallichianum > Portulaca oleraceae. From the results it can be assumed that the phyto-toxic effects of the aforementioned plants could be helpful in searching and development of new pharmaceuticals that can be used as positive sources for the development of new weedicides.

Keywords: Allelopathy; Lactuca sativa; Medicinal Plants; Phyto-toxic Potential

\section{Introduction}

Plants of toxic nature can be used as natural herbicides or these phyto toxic components of interest can be extracted from the plants for developing new herbicides. A variety of plant's metabolites used to inhibit or stimulate the growth and development of other plants. These chemicals are called allelochemicals which exudated out, leached from different parts of plant or volatiled or plant residues present in the environment [1].
The effect of allelochemicals is called allelopathy which is the effects of donor plant, on recipient plant by the discharge of chemicals in the environment. This activity influences the growth and development of other plants either by inhibiting or stimulating the bio-physiologic processes of recipient organism. These activities are concentration dependent and might inhibit the growth of one plant at one concentration and might stimulate the growth at other 
concentration. Such chemical are present in different plant parts in high amounts at specific environmental conditions [2]. Environmental conditions are responsible for differences in concentration of these metabolites [3].

Germination of seeds and plant development is altered by allelopathy and therefore germination is important way for the learning of allelopathy. Allelopathy has a significant part in agriculture and disturbs the progress and magnitude of the crops by the exchange of chemicals among crops, weeds and trees. Allelochemicals secreted by unknown plants significantly affect the intrinsic plants regardless of native species secreted allelochemicals or not [4]. Allelochemicals can alter the contents of plant growth hormones or make inequalities in many phyto-hormones, which hinders plant growth and development, for instance, with respect to germination of seed and sapling growth. Allelochemicals of phenolic nature can motivate IAA oxidase activity and obstruct the reaction of POD with IAA, unavoidable GA or IAA to effect endogenous hormone stages [5]. Fujii et al. [6] evaluated the allelopathic activities of 239 medicinal species using the sandwich method and 223 species of them were found to inhibit the seeds germination, while 17 species were found to stimulate lettuce radicle growth. Fujii et al. [7] reported the allelopathic effect from leaf mess leachates on lettuce seed germination and found inhibitory action determined by the sandwich method. Gilani et al. [8] screened 81 Pakistani medicinal plants and found that plants with allelopathic potentials also have stimulatory effects side by side with inhibition.

Medicinal plants like Carum carvi L., Coriandrum sativum and Foeneculum vulgare also inhibit the growth of weeds [9]. Lavendula angustifolia, Mentha longifolia and $M$. piperrita reduces germination of Sorghum helapence and Rumex crispus [10].
Nekonam et al. [11] also investigated medicinal plants which possess herbicidal properties against Amaranthus retroflexus. Zahedi and Ansari [12] investigated allelopathic potential of mallow extract and leachates on crop. Use of medicinal plants having phytotoxic property possess significant role in weeds control. Plant residues of Artemisia reduces seed germination of Agropyron repens [13]. Any part of the plant contained chemicals which might be allelochemicals, become part of the environment through root-exudates, leaching from upper plant parts or by decomposing of plant parts [14]. New botanical insecticides which are basically obtained from plants, are very necessary to overcome the resisting population of insects and have minimum or low threats to the environment. The present investigation was undertaken to evaluate medicinal plants for allelopathic property to produce harmless fumigant or insecticides that must be operative, cheap and suitable to use.

\section{Materials and methods}

Allelopathic study was carried out using sandwich method of Fujii et al. $[6,7]$ with slight modification. In this method $15 \mathrm{~g}$ agar was dissolved in 1liter of distilled water and was autoclaved. The agar solution was left to cool at room temperature but before to solidify completely, the agar solution was poured into sterilized petriplates kept to solidify. Dehydrated plant material of each selected medicinal plant of $10 \mathrm{mg}, 20 \mathrm{mg}$ and $40 \mathrm{mg}$ were placed on the agar in petriplate and again a layer of agar was spread over it. After complete solidification, ten seeds of lettuce (Lactuca sativa L.) were employed on agar-gel in petriplate. Petriplates were wrapped with plastic-tape and nurtured for 72 $h$ at $24^{\circ} \mathrm{C}$ in dark environments. The sizes of radicle and plumule were noted in $(\mathrm{cm})$. Only agar without any plant material was used as a seed bed for lettuce seeds in control set of petriplates. 
Each treatment was repeated three times. Means of radicle and plumule lengths for each medicinal plant were measured by relating to that of control. The data was evaluated statistically for the $10 \mathrm{mg}, 20 \mathrm{mg}$ and $40 \mathrm{mg}$ of plant materials with radicle and plumule lengths of selected medicinal plants.

\section{Results and discussion}

Medicinal plants have inhibitory or stimulatory effects on selected whether cultivated or weeds and it's their allelochemicals inhibiting or promoting the plant growth. It is easy to separate allelopathic plants from medicinal plants due to their capability of accumulation of specific metabolitess which can cure numerous infections of manhood [15-17]. Plants possess toxic metabolites can be potential bases bio-herbicides. Climatic and various ecological conditions may alter the plant metabolites and ultimately their synthesis of these components [18]. The use of cultivated crops as soil cover have many possible profits such as increasing oil fertility, upgrade soil inclination, enhanced nitrogen fixing ability, reducing corrosion, stop leakage of nutrients and clamping down the weed production. Chemicals are used to reduce growth of weeds which inversely affect the crop production. Struggle for nutrients and production of biochemicals by the crops can reduce the weed density and enhances the growth of crops because these chemicals have adverse effect on weeds. Releasing allelopathic Chemicals and production of primary or secondary metabolites by the crops over weeds, these chemicals interfering growth properties of the weeds which in turn either proved toxic or stimulate their growth. Allelopathy is chemical communication between the donor and recipient plant [19]. For allopathic study sandwich method of Fujii et al., [6, 7] was used, in which lactuca sativa seeds were used in agar gel bedding with different amount of plants parts pieces. Viveros-Legorreta et al. [20] reported that
OECD (Organisation for Economic Cooperation and Development), US-EPA (USEnvironmental Protection Agency) and USFDA (US-Food and Drug Administration), recommend that the most sensitive dicotyledons species: Cucumis sativus, Lactuca sativa, Raphanus sativus, Trifolium pratensis, and monocotyledons species: Triticum aestivum and Panicum miliaceum tested by diverse authors can be used in germination experiments [21]. Pino et al. [22] reported that pharmaceuticals cause inhibition of the radicle and hypocotyl elongation of Lactuca sativa. Allopathic chemicals are mostly absorb by radicle because it appear prior to plumule that's why its growth is more inhibited than the plumule [23].

The results of the Phytotoxicity/ allelopathy of selected medicinal in present study indicated that seeds of Lactuca sativa respond differentially to different medicinal plants (Table 1). At 10mg dose seeds of Lactuca sativa were very susceptible to leaves fragments of Monotheca buxifolia with radicle length of $0.18 \mathrm{~cm}$, followed by Cucumis sativus seeds powder with radical length of $0.26 \mathrm{~cm}$ and Malus baccata with radicle length of $0.64 \mathrm{~cm}$. Portulaca oleracae and Geranium wallichianum showed stimulatory effect on seeds of Lactuca sativa (Fig.1). Libralato et al. [24] reported the Phytotoxicity of zerovalent iron on Lepidium sativum, Sinapis alba and S. saccharatum, their results showed bio stimulation effects as increased seedling length and high biomass. At $10 \mathrm{mg}$ concentration plumule growth was also inhibited by Cucumis sativus $(0.22 \mathrm{~cm})$, Monotheca buxifolia $(0.24 \mathrm{~cm})$ and Malus baccata with $1.18 \mathrm{~cm}$ length of plumule. Saxifraga flagillaris, Portulaca oleraceae and Geranium wallichianum showed stimulatory effects (Fig. 2). It is also reported that the chemicals of different part of the same plant can showed phytotoxic, inhibitory 
or stimulatory effects on other recipient plants. Mehmoodzadeh et al. [25] reported the allelopathic effect of Cannabis sativa shoot and root extract where shoot showed inhibitory effects while root gave stimulatory effects on seeds of Lactuca sativa.

Present study showed that at $20 \mathrm{mg}$ radicle length of Lactuca sativa was least with Monotheca buxifolia (0.12), followed by Cucumis sativus (0.14) and Malus baccata (0.63). Portulaca oleracae, Geranium wallichianum and Saxifraga flagillaris showed $1.74,1.82 \mathrm{~cm}$ and $2.38 \mathrm{~cm}$ length of radicle respectively (Fig. 3). Naz and Bano [26] reported that leaf extracts of $R$. communis and L. camara inhibit the growth of maize seedlings. Similar studies was conducted by Algandaby and Salama [17] where medicinal plants showed good phytotoxic or allelopathic effect. Devkota and Sherma [27] also screened allelopathy of rhizome and leaves of justice adhatoda where they reported inhabited germination of wheat and pea seeds.

The present findings showed at $20 \mathrm{mg}$ conc. Malus baccata reduces Plumule length and was $0.03 \mathrm{~cm}$, followed by Monotheca buxifolia with $0.13 \mathrm{~cm}$ and Cucumis sativus with $0.16 \mathrm{~cm}$. Saxifraga flagillaris, Portulaca oleraceae and Geranium wallichianum showed 1.54, 2.47 and $2.69 \mathrm{~cm}$ length of plumule respectively (Fig. 4). Monotheca buxifolia inhibited the growth of Lactuca sativa might be due to the presence of flavonoids present there in. Macdonald et al. [28] reported that Ocimum gratissimum flavonoids are phytotoxic. Jan et al. [29] reported the presence of flavonoids in Monotheca buxifolia. Same results were reported by Saadullah et al. [30].

At $40 \mathrm{mg}$, radicle length of Lactuca sativa seeds was least Monotheca buxifolia (0.12), followed by Cucumis sativus (0.14) and Malus baccata (0.63). Portulaca oleracea, Geranium wallichianum and Saxifraga flagillaris showed $1.74,1.82 \mathrm{~cm}$ and $2.38 \mathrm{~cm}$ length of radicle respectively (Fig. 5) while plumule length at $40 \mathrm{mg}$ was least $(0.09 \mathrm{~cm})$ with Cucumis sativus, followed by Monotheca buxifolia $(0.15 \mathrm{~cm})$ and Malus baccata $(0.66 \mathrm{~cm})$. Portulaca oleraceae, Geranium wallichianum and Saxifraga flagillaris showed $1.82,1.15 \mathrm{~cm}$ and $2.30 \mathrm{~cm}$ respectively (Fig. 6). These plants use in present study are commonly used for treating various illnesses but their allelopathic potentials are not reported yet. It is reported that medicinal plants can also be good sources of novel herbicides by inhibiting the growth seeds in vivo [31, 32]. It revealed from previous work that medicinal plants can produce inhibitory allelochemicals which reduces the germination of weeds [33].

The toxicity of many plants has been attributed to the point linked to their existence in their surroundings. According to Rasoanaivo et al. [34] toxic and lethal plants particularly those rising in the wild must have in their evolutionary antiquity, established multifaceted substances as survival machinery to defend themselves from their predators. An opinion arises that some of the herbal biochemical mixtures may be operative in offensive cancer cells or deactivating eukaryotic ribosomes [35]. Phytotoxic medicinal plants are good springs of antitumor complexes, immune-toxines, steroid and non-steroid cardio active drugs. They are convenient to humanity. Herbal medicine experts and scientists are conscious of the possible toxicity of medicinal plants and they have formulated numerous means of removing the toxins or escaping the toxic fragments of the plants. Phytotoxicity tests are also directed to determine the toxicity of medicinal plants. The study was conducted that to check the effects of chemicals present in the donor plants on to the recipient plant. Using of more than one plant in bioassay can clearly measure the allelopathic potential of the donor plants on to recipient plant which 
can lead us to isolation of new compounds of biological positive activity $[36,37]$.

Table. 1 Allelopathic effect of selected medicinal plants on seeds of Lactuca sativa

\begin{tabular}{|c|c|c|c|c|c|c|c|}
\hline S. No. & Plants names & \multicolumn{2}{|c|}{ 10mg } & \multicolumn{2}{c|}{ 20mg } & \multicolumn{2}{c|}{ 40mg } \\
\hline & & Radicle & Plumule & Radicle & Plumule & Radicle & Plumule \\
\hline \multirow{2}{*}{1} & Cucumis & 0.26 & 0.22 & 0.09 & 0.16 & 0.14 & 0.09 \\
& sativus & \pm 0.14 & \pm 0.12 & \pm 0.04 & \pm 0.07 & \pm 0.07 & \pm 0.04 \\
\hline \multirow{2}{*}{2} & Portulaca & 3.86 & 3.86 & 1.97 & 2.47 & 1.74 & 1.82 \\
& oleracea & \pm 0.23 & \pm 0.24 & \pm 0.16 & \pm 0.17 & \pm 0.11 & \pm 0.13 \\
\hline \multirow{2}{*}{3} & \multirow{2}{*}{ Malus baccata } & 0.64 & 1.18 & 0.44 & 0.3 & 0.63 & 0.66 \\
& Saxifraga & \pm 0.07 & \pm 0.06 & \pm 0.02 & \pm 0.02 & \pm 0.07 & \pm 0.10 \\
\hline \multirow{2}{*}{4} & flagillaris & \pm 0.06 & \pm 0.091 & \pm 0.19 & \pm 0.16 & \pm 0.16 & \pm 0.11 \\
& Geranium & 3.083 & 2.68 & 3.71 & 2.69 & 1.82 & 1.15 \\
\multirow{2}{*}{5} & wallichianum & \pm 0.15 & \pm 0.15 & \pm 0.17 & \pm 0.16 & \pm 0.11 & \pm 0.09 \\
\hline \multirow{2}{*}{6} & Monotheca & 0.18 & 0.24 & 0.04 & 0.13 & 0.12 & 0.15 \\
& buxifolia & \pm 0.09 & \pm 0.13 & \pm 0.01 & \pm 0.02 & \pm 0.01 & \pm 0.02 \\
\hline
\end{tabular}

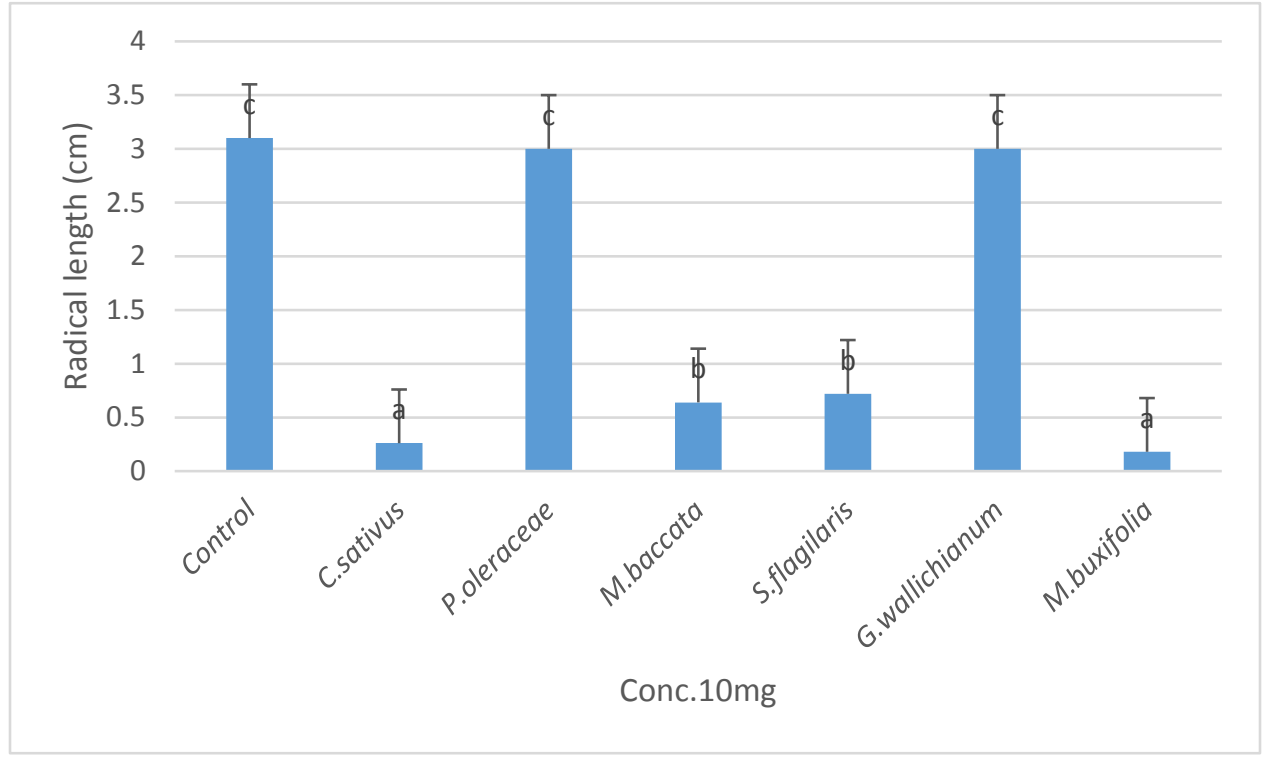

Figure 1. At 10mg concentration (dry powdered parts of plants), allelopathic effects of selected medicinal plants parts on Radical length of lettuce seeds 


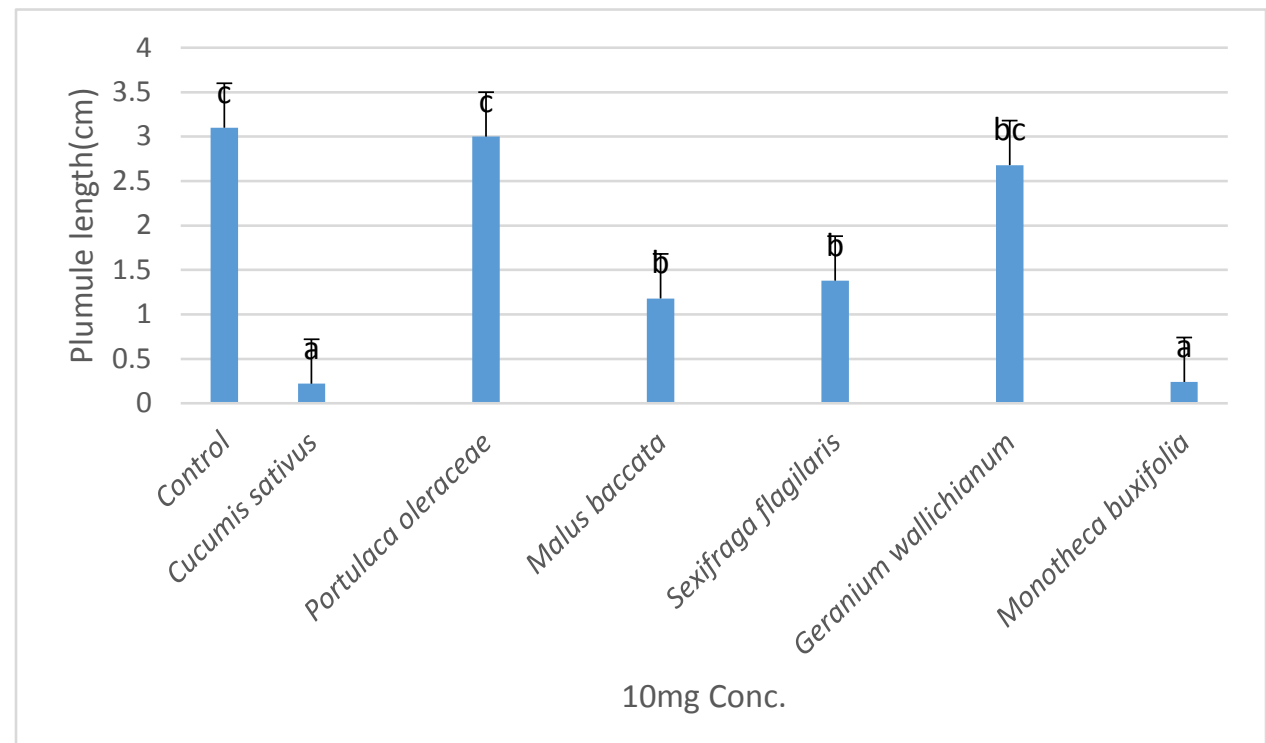

Figure 2. At $10 \mathrm{mg}$ concentration (dry powdered parts of plants), allelopathic effects of selected medicinal plants parts on Plumule length of lettuce seeds

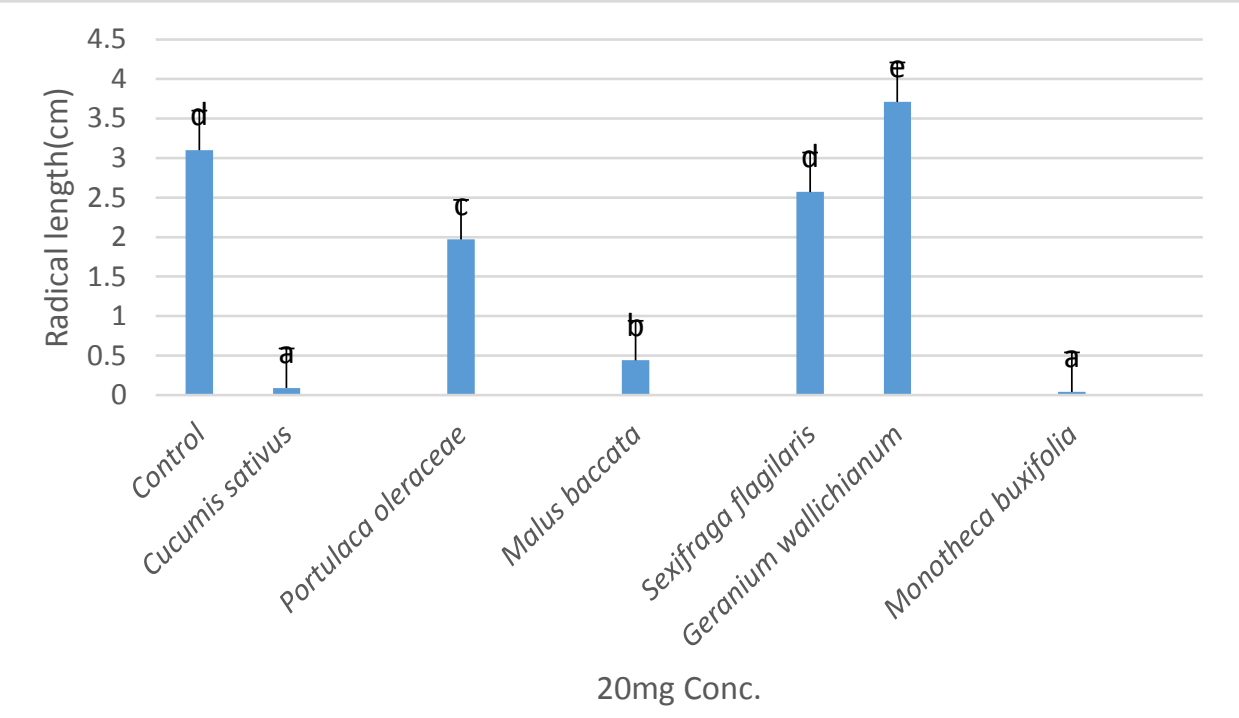

Figure 3. At $20 \mathrm{mg}$ concentration (dry powdered parts of plants), allelopathic effects of selected medicinal plants parts on Radical length of lettuce seeds 


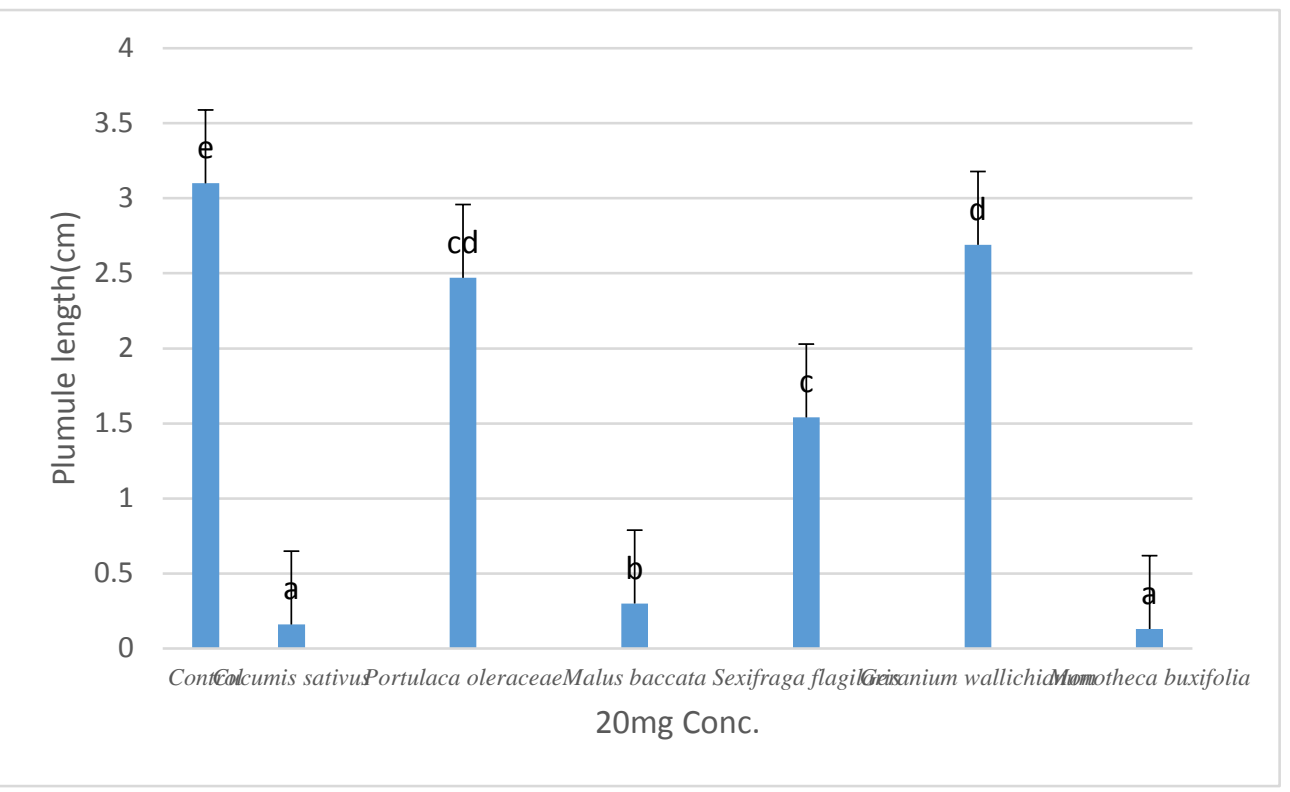

Figure 4. At $20 \mathrm{mg}$ concentration (dry powdered parts of plants), allelopathic effects of selected medicinal plants parts on Plumule length of lettuce seeds

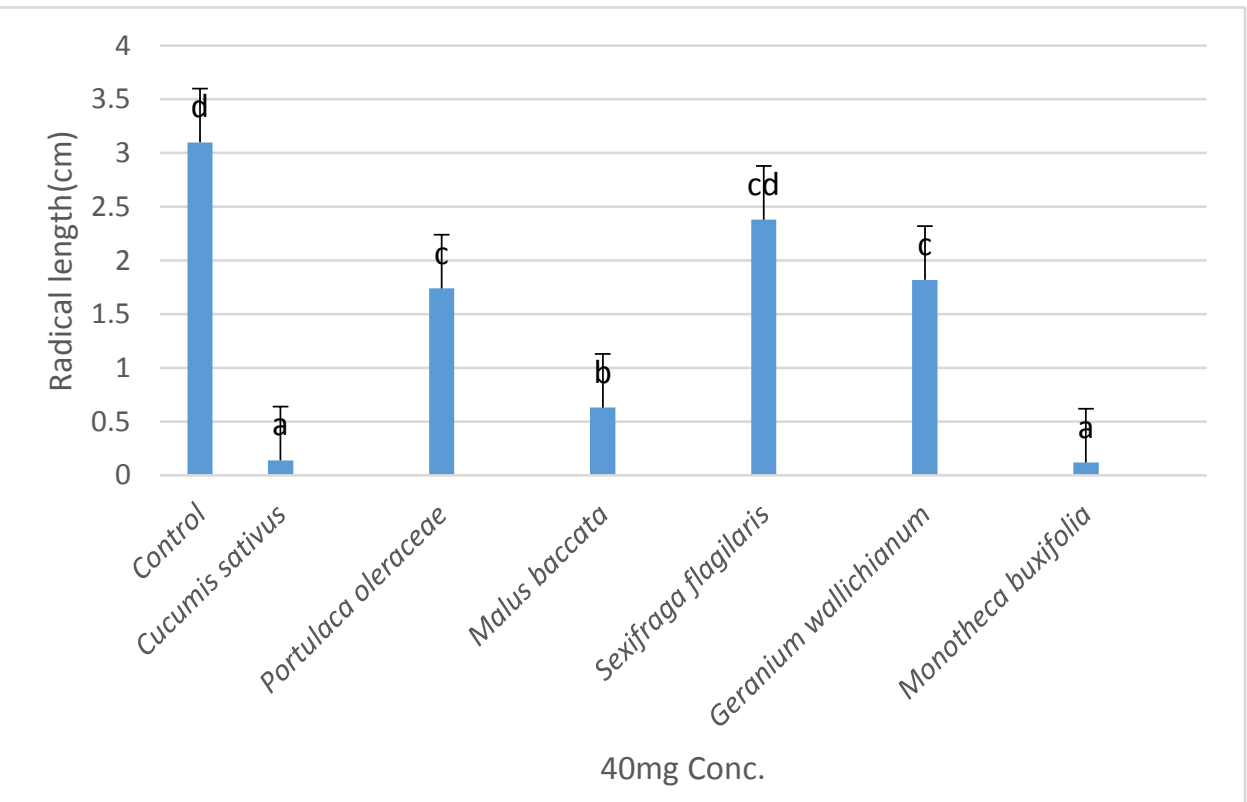

Figure 5. At 40mg concentration (dry powdered parts of plants), allelopathic effects of selected medicinal plants parts on Radical length of lettuce seeds 


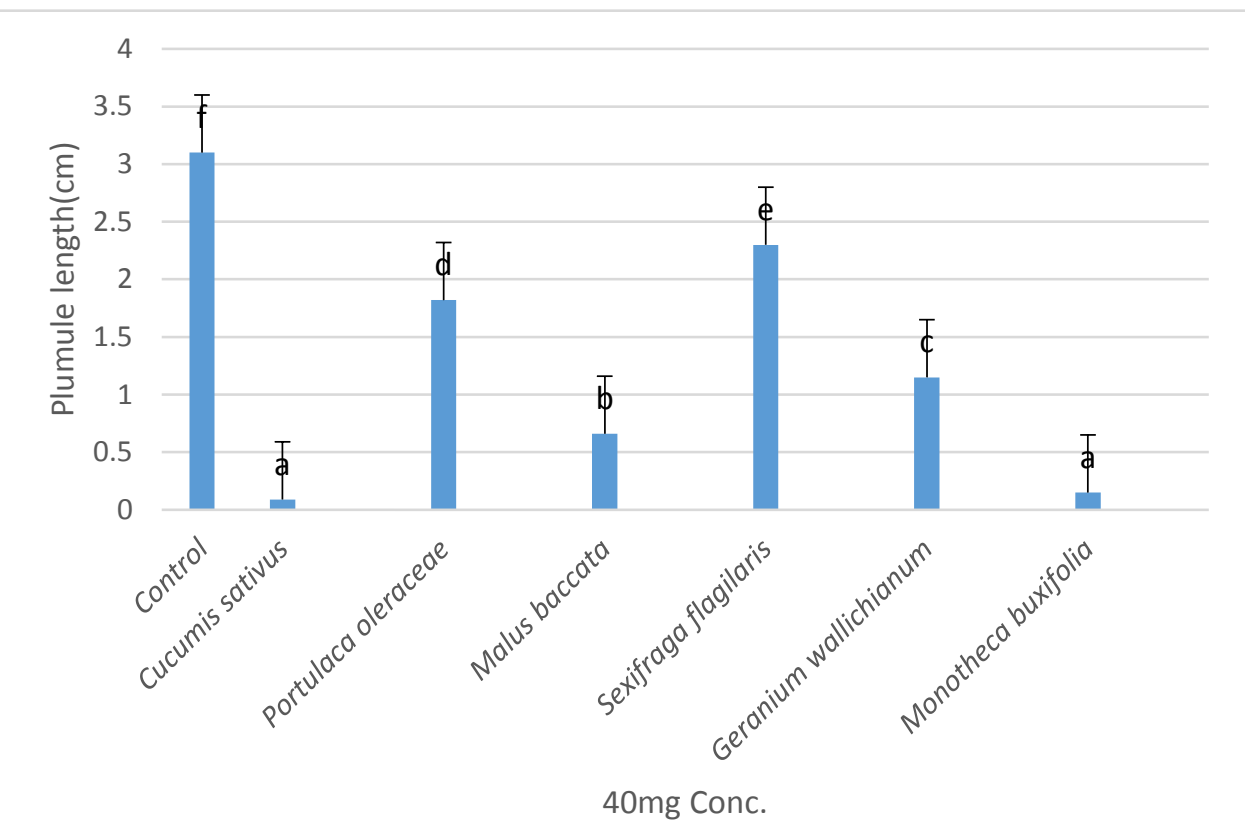

Figure 6. At $40 \mathrm{mg}$ concentration (dry powdered parts of plants), allelopathic effects of selected medicinal plants parts on Plumule length of lettuce seeds

\section{Conclusion}

It is concluded from the present study that medicinal plants not only cure illnesses but also possess strong allelochemicals which either could inhibit the growth of radicals or plumule but have stimulatory effects too. These plants have many important chemical like phenols etc. which will be involve in the overall process. In present study the plants which show good inhibitory effects against Lactuca sativa, needs further examination against weeds and crops in open fields. It is also important to isolate inhibitory compounds from these selected medicinal plant which might be ecofriendly and to control weeds.

\section{Authors' contributions}

Conceived and designed the experiments: $\mathrm{M}$. Humayun, Performed the experiments: HA Begum, Analyzed the data: HA Begum, Contributed materials/ analysis/ tools: M. Humayun, Wrote the paper: HA Begum.

\section{References}

1. Dastagir G \& Hussain F (2013). Phytotoxic and insecticidal activity of plants of family Zygophyllaceae and Euphorbiaceae. Sarhad J Agri 29(1): 8391.

2. Shinwari MI \& Fujii Y (2013). Allelopathic activity of medicinal plants and weeds from Pakistan. Allelopathy $J$ 32(2): 223.

3. Ncube B, Finnie JF \& Van Staden J (2012). Quality from the field: the impact of environmental factors as quality determinants in medicinal plants. South African J of Bot 82: 11-20.

4. Ramgunde V \& Chaturvedi A (2016). Allelopathic effect of Ricinus communis L. and Vitex negundo L. on morphological attributes of invasive alien weed: Cassia uniflora Mill. IRAInter J of Appl Sci 3(3).

5. Cheng F, \& Cheng Z (2015). Research Progress on the use of Plant Allelopathy in Agriculture and the Physiological and Ecological Mechanisms of Allelopathy. Frontiers in Plant Sci 6 1020. 
6. Fujii Y, Parvez SS, Parvez ., Ohmae Y \& Iida O (2003). Screening of 239 medicinal plant species for allelopathic activity using the sandwich method. Weed Biol and Manag 3(4): 233-241.

7. Fujii Y, Shibuya T, Nakatani K, Itani T, Hiradate S \& Parvez MM (2004). Assessment method for allelopathic effect from leaf litter leachates. Weed Biol and Management 4(1): 19-23.

8. Gilani SA, Fujii Y, Shinwari ZK, Adnan M, Kikuchi A \& Watanabe KN (2010). Phytotoxic studies of medicinal plant species of Pakistan. Pak J Bot 42(2): 987-996.

9. Dikic M (2005). Allelopathic effect of cogermination of aromatic and medicinal plants and weed seeds. Herbologia 6(1): 15-24.

10. Petrova ST, Valcheva EG \& Velcheva IG (2015). A Case Study of Allelopathic Effect on Weeds in Wheat. Ecologia Balkanica 7(1).

11. Nekonam MS, Razmjoo J, Kraimmojeni $\mathrm{H}$, Sharifnabi B, Amini H \& Bahrami F (2014). Assessment of some medicinal plants for their allelopathic potential against redroot pigweed (Amaranthus retroflexus). J of Plant Protec Res 54(1): 90-95.

12. Zahedi SM \& Ansari NA (2011). Allelopathic potential of common mallow (Malva sylvestris) on the germination and the initial growth of tomato, cucumber and cress. Asian $J$ of Agri Sci 3(3): 235-241.

13. Balicevic R, Ravlić M \& Ravlić I (2015). Allelopathic effect of aromatic and medicinal plants on Tripleurospermum inodorum (L.)

$\mathrm{CH}$

Schultz. Herbologia 15(2): 40.

14. Verma SK, Kumar S, Pandey V, Verma RK \& Patra DD (2012). Phytotoxic effects of sweet basil (Ocimum basilicum L.) extracts on germination and seedling growth of commercial crop plants. Euro J of Experimental Biol 2(6): 2310-2316.

15. Nasreen S, Luby SP, Brooks WA, Homaira N, Al Mamun A, Bhuiyan MU, Rahman M, Ahmed D, Abedin J, Rahman M \& Alamgir ASM (2014). Population-based incidence of severe acute respiratory virus infections among children aged $<5$ years in rural Bangladesh, June-October 2010. PloS One 9(2): 89978.

16. Hemada MM \& El-Darier SM (2015). Management of A Noxious Weed; Melilotus indicus L. via Allelopathy of Cotula cinerea Del. Inter J 3(3): 553561.

17. Algandaby MM \& Salama M (2016). Management of the noxious weed; Medicago polymorpha L. via allelopathy of some medicinal plants from Taif region, Saudi Arabia. Saudi J of Biol Sci.

18. Pinto GFDS \& Kolb RM (2015). Seasonality affects phytotoxic potential of five native species of Neotropical savanna. Bot 94(2): 81-89.

19. La Hovary C, Danehower DA, Ma G, Reberg-Horton C, Williamson JD, Baerson SR \& Burton JD (2016). Phytotoxicity and Benzoxazinone Concentration in Field Grown Cereal Rye (Secale cereale L.). Inter $J$ of Agro 2016.

20. Viveros-Legorreta JL, Sarma SSS, Guerrero-Zúñiga LA, \& RodríguezDorantes A (2016). Effect of the nature of Ceratophyllum demersum extracts on Lactuca sativa seedlings. Inter J Curr Res Biosci Plant Biol 3(7): 65-72.

21. Visioli G, Conti FD, Gardi C \& Menta C (2014). Germination and root elongation bioassays in six different plant species for testing $\mathrm{Ni}$ contamination in soil. Bulletin of Environ Contamination and Toxicol 92(4): 490-496.

22. Pino MR, Muñiz S, Val J \& Navarro E (2016). Phytotoxicity of 15 common 
pharmaceuticals on the germination of Lactuca sativa and photosynthesis of Chlamydomonas reinhardtii. Environ Sci and Pollution Res 23(22): 2253022541.

23. Gniazdowska A \& Bogatek R (2005) Allelopathic interaction between plants. Multi-site action of allelochemicals. Acta Physiol Plant 27: 395-407

24. Libralato G, Devoti AC, Zanella M, Sabbioni E, Mičetić I, Manodori L, Pigozzo A, Manenti S, Groppi F \& Ghirardini AV (2016). Phytotoxicity of ionic, micro-and nano-sized iron in three plant species. Ecotoxicol and Environ Safety 123: 81-88.

25. Mahmoodzadeh H, Ghasemi M \& Zanganeh H (2015). Allelopathic effect of medicinal plant Cannabis sativa L. on Lactuca sativa L. seed germination. Acta agriculturae Slovenica 105(2): 233-239.

26. Naz R \& Bano A (2014). Effects of Allelochemical Extracts from Medicinal Plants on Physiological and Biochemical Mechanisms of Maize (Zea mays L.) Seedlings. Inter $J$ of Agro and Agric Res 5: 31-39.

27. Devkota A \& Sharma S (2014). Allelopathic Potential of Medicinal Plants: Costus speciosus Koen ex. Retz and Justicia adhatoda Linn. J of Nat His Museum 28: 57-65.

28. Macdonald IO, Oludare AS \& Olabiyi A (2010). Phytotoxic and anti-microbial activities of flavonoids in Ocimum gratissimum. Life Sci J 7: 3.

29. Jan S, Khan MR, Rashid U \& Bokhari J (2013). Assessment of antioxidant potential, total phenolics and flavonoids of different solvent fractions of
Monotheca buxifolia fruit. Osong Pub Health and Res Persp 4(5): 246-254

30. Saadullah M, Chaudary BA \& Uzair M (2016). Antioxidant, Phytotoxic and Antiurease Activities, and Total Phenolic and Flavonoid Contents of Conocarpus lancifolius (Combretaceae). Tropical J of Pharmaceutical Res 15(3): 555-561.

31. Nasrine S, El-Darier SM \& El-Taher HM (2011). Allelopathic effect from some medicinal plants and their potential uses as control of weed. In Inter Conf Biol Environ Chem 24: 15-22.

32. Suwitchayanon P, Kunasakdakul K \& Kato-Noguchi H (2017). Screening the allelopathic activity of 14 medicinal plants from Northern Thailand. Environ Control in Biol 55(3): 143-145.

33. Sharma S \& Devkota A (2015). Allelopathic potential and phytochemical screening of four medicinal plants of Nepal. Scientific World 12(12): 56-61.

34. Rasoanaivo P, Petitjean A, Ratsimamanga-Urverg S \& RakotoRatsimamanga A (1992). Medicinal plants used to treat malaria in Madagascar. $J$ of Ethnopharmacol 37(2): 117-127.

35. Monsurat WO (2016). Phytotoxicity in Herbal Medicine: A Review. New York Sci 9(1): 1-8.

36. Rahman MM, Wahed MII, Biswas MH, Sadik GM \& Haque ME (2001). In vitro antibacterial activity of the compounds of Trapa bispinosa Roxb. Sci 1: 214216.

37. Wink M (2015). Modes of action of herbal medicines and plant secondary metabolites. Medicines 2(3): 251-286. 